\title{
Application of an Accurate and Validated Method for Identification and Quantification of Acrylamide in Bread, Biscuits and Other Bakery Products Using GC-MS/MS System
}

\author{
Mioara Negoiță and Alina Culețu* \\ National Institute of Research \& Development for Food Bioresources, IBA Bucharest, 6 Dinu \\ Vintila, 021102 Bucharest, Romania
}

\begin{abstract}
A gas chromatography tandem mass spectrometry has been developed and validated for the separation, detection, identification and quantification of acrylamide in bread, biscuits and similar products. The method showed good precision with values lower than $6 \%$. A good sensitivity was achieved for bread with 2.41 and $7.23 \mu \mathrm{g} \mathrm{kg}^{-1}$ limit of detection (LOD) and limit of quantification (LOQ), respectively, while for biscuits, LOD and LOQ were 4.63 and $13.89 \mu \mathrm{g} \mathrm{kg}^{-1}$, respectively. Accuracy obtained through the bias of 2 certified reference materials ("crisp bread - ERM ${ }^{\circledR}$ BD272" and "rusk - ERM ${ }^{\circledR}$-BD274") gave a value below 1.68-2.52\%. The method was applied by analyzing 49 types of bread, biscuits and other similar products. The results showed different levels of acrylamide in bread (values ranged between 7.6 and $165.6 \mu \mathrm{g} \mathrm{kg}^{-1}$ ), biscuits (between LOD and $2405.0 \mu \mathrm{g} \mathrm{kg}^{-1}$ ), sandwich biscuits with cream (112.6-570.4 $\mathrm{g} \mathrm{kg}^{-1}$ ), biscuits for infants and young children (between LOD and $801.7 \mu \mathrm{g} \mathrm{kg}^{-1}$ ), gingerbread (349.5-955.5 $\mu \mathrm{g} \mathrm{kg}^{-1}$ ) and crackers $\left(347.8-366.1 \mu \mathrm{g} \mathrm{kg}{ }^{-1}\right)$.
\end{abstract}

Keywords: acrylamide (AA), validation, bread, biscuits, GC-MS/MS

\section{Introduction}

Acrylamide (AA) is a chemical that can be formed in some foods during certain types of high-temperature cooking. The neurotoxicity of AA in humans is well established from occupational and accidental exposures, and experimental studies have shown reproductive, genotoxic and carcinogenic effects in animals. AA has been classified as probably carcinogenic to humans by the International Agency for Research on Cancer (IARC). ${ }^{1}$ The possible public health risks from dietary exposure to AA attracted concern by public authorities all over the world. ${ }^{2}$

Based on the expert committee evaluation of FAO/ WHO, $1 \mu \mathrm{g} \mathrm{kg}^{-1}$ body weight (bw) day ${ }^{-1}$ is considered as an average exposure to AA while $4 \mu \mathrm{g} \mathrm{kg}^{-1}$ bw day ${ }^{-1}$ is considered as high exposure to AA. ${ }^{3}$ The mean dietary exposure range to AA is $0.2-1.0 \mu \mathrm{g} \mathrm{kg}^{-1}$ bw day ${ }^{-1}$ for the general adult population while 95th-percentile range is 0.6-1.8 $\mu \mathrm{g} \mathrm{kg}^{-1}$ bw day ${ }^{-1} .{ }^{4}$ In 2013, the U.S. Food and Drug Administration (FDA) $)^{5}$ issued draft guidance to help the food industry to reduce the amount of AA in certain foods.

*e-mail: alinaculetu@gmail.com
Commission Recommendation 2013/647/EU established, based on the monitoring results received from the Member States during the period 2007-2012, the "indicative values" for AA in different foods. The "indicative values" are not safety thresholds, but their aim is to indicate the need for an investigation in the case the values are exceeded and to take appropriate measures to control the formation of AA. ${ }^{6}$

Taking into account that the presence of AA in food products could increase the risk of cancer in consumers of all ages, ${ }^{7,8}$ an internationally priority is to develop reliable analysis method to quantify low concentrations of AA in foods (dozens of ppb) and to find solutions to reduce this contaminant. Worldwide, in recent years several methods have been developed for the determination of AA from food products. ${ }^{9-11}$

Although in the last decade were published a large number of analytical methods based on gas chromatography (GC) $)^{12-17}$ and liquid chromatography (LC) coupled with mass spectrometry (MS; MS/MS), ${ }^{18-22}$ the methods are mainly used by private laboratories and official control authority for routine analysis of AA in food products. Last publications apparently confirm the validity of LC and GC techniques, which enables to guarantee the determination 
of AA with quantification limits from 30 to $50 \mu \mathrm{g} \mathrm{kg}-1$ for HPLC-MS, 4 to $30 \mu \mathrm{g} \mathrm{kg}^{-1}$ for GC-MS and LC-MS/MS. Commission recommendation of 2 June 2010, states that for ensuring comparability of analytical results, methods that can achieve a limit of quantification (LOQ) of $30 \mu \mathrm{g} \mathrm{kg}^{-1}$ for bread and foods for infants and young children and $50 \mu \mathrm{g} \mathrm{kg}^{-1}$ for potato products, other cereal products, coffee and other products should be chosen. ${ }^{23}$

The aim of this study is to present the results obtained on internal validation of GC-MS/MS method for determination of AA in bread, biscuits and other similar products with LOQ below the above recommended values. Moreover, assessing the level of AA in some bakery products from the Romanian market was performed.

\section{Experimental}

\section{Sampling}

Seventeen types of bread and similar products, 18 types of biscuits, 5 types of biscuits for infants and young children, 4 types of sandwich biscuits, 2 crackers and 3 gingerbread were studied. Samples were either purchased in local market (various types produced in different countries) or produced on a pilot plant of the National Research \& Development Institute for Food Bioresources (Romania).

\section{Chemicals and reagents}

Native acrylamide (min. 99\% purity, concentration $1000 \mathrm{mg} \mathrm{L}^{-1}$ in methanol) (AA) was purchased from Ultra Scientific (N. Kingstown, Rhode Island, USA), internal standard of labeled acrylamide $\left(1,2,3-{ }^{13} \mathrm{C}\right.$ labelled AA) (IS), $\min .99 \%$ purity (+100 ppm hydroquinone) of concentration of $1000 \mathrm{mg} \mathrm{L}^{-1}$ in methanol was from Cambridge Isotope Laboratories, Inc. (Andover, MA, USA). All other reagents used during the validation of the method for determination of AA were of chromatographic purity from Merck (Darmstadt, Germany), LGC Promochem GmbH (Wesel, Germany) and Scharlau (Sentmenat, Spain). Ultrapure water was obtained through a PURELAB Option-S7 and PURELAB Ultra Ionic system (Elga Labwater, High Wycombe, UK).

Carrez I and II solutions were prepared by dissolving $28.8 \mathrm{~g}$ of potassium hexacyanoferrate and $57.6 \mathrm{~g}$ of zinc sulfate in $100 \mathrm{~mL}$ of water, respectively.

Helium as mobile phase (min. 99.9995\%) and argon (min. 99.9995\%) as collision gas were used. Samples concentration was achieved under a stream of nitrogen (min. 99.9995\%).

Reference test materials ERM ${ }^{\circledR}-\mathrm{BD} 272$ crispbread (AA content of $980 \pm 90 \mu \mathrm{g} \mathrm{kg}^{-1}$ ) and ERM ${ }^{\circledR}-\mathrm{BD} 274$ rusk
(AA content of $74 \pm 7 \mu \mathrm{g} \mathrm{kg}^{-1}$ ) were certified at the BAM Federal Institute for Materials Research and Testing (Berlin, Germany) to verify the accuracy of the method.

\section{Preparation of stock and working solutions}

Stock solution of AA (100 mg L $\left.\mathrm{L}^{-1}\right)$ and IS (100 mg L-1) were prepared in amber vials by dissolving in ultrapure water. Working solutions I, II and III (10, 1 and $0.1 \mathrm{mg} \mathrm{L}^{-1}$ of AA, respectively) and working solution I (10 $\left.\mathrm{mg} \mathrm{L}^{-1}\right)$ of IS were prepared by diluting the stock solution with ultrapure water. All stock and working solutions were kept in a refrigerator at $4{ }^{\circ} \mathrm{C}$.

\section{Sample preparation}

The procedure of sample preparation for AA quantification in bread, biscuits and other bakery products was according to previous study ${ }^{13-15}$ with some modifications ${ }^{24,25}$ regarding sample preparation (sample preparation for soft bread, sample weight taken for analysis, quantities and volumes for reagents) and AA analysis by GC-MS/MS in selected reaction monitoring (SRM) acquisition mode, respectively. Briefly, the steps were as follow:

\section{Drying, milling and weighting}

Only fresh bread samples were dried in an oven at $90{ }^{\circ} \mathrm{C}$, for $120 \mathrm{~min}$, while biscuits and other similar products were used as they were. The samples were fine milled using a Retch GM 200 mill (Germany) and an ultra centrifugal ZM 200 mill (Germany). In a centrifuge vial of $50 \mathrm{~mL}, 3 \mathrm{~g}$ of "bread and other similar products" and $1.5 \mathrm{~g}$ from "biscuits and other similar products" category were weighed for AA analysis, respectively.

\section{AA extraction in water}

Over the sample weighed, working solution I of the IS of $10 \mathrm{mg} \mathrm{L}^{-1}(110 \mu \mathrm{L})$ and $30 \mathrm{~mL}$ ultrapure water at $60^{\circ} \mathrm{C}$ were added. Extraction in water at $\mathrm{pH} 4-5$ was achieved by addition of $20-40 \mu \mathrm{L}$ of glacial acetic acid, followed by deproteinization with $400 \mu \mathrm{L}$ Carrez I and II solutions and centrifugation $(6000 \times \mathrm{g})$ at $5{ }^{\circ} \mathrm{C}$, for $30 \mathrm{~min}$.

\section{AA derivatization}

The supernatant obtained was derivatized with 7.5 g KBr, 40-100 $\mu \mathrm{L} \mathrm{HBr} \mathrm{(pH} \mathrm{1-3),} 10 \mathrm{~mL}$ saturated bromine-water solution (around 1.6\%) on a shaking water bath below $4{ }^{\circ} \mathrm{C}$, for at least $2 \mathrm{~h}$. After the end of the derivatization reaction, bromine in excess was removed by adding around 1-2.5 mL of $1 \mathrm{~mol} \mathrm{~L}^{-1}$ sodium thiosulfate, until the yellow color disappeared. 


\section{Extraction of dibromo derivative of AA 2,3-dibromopropanal (2,3-DBPA)}

It was achieved with $70 \mathrm{~mL}$ mixture of ethyl acetate and hexane $(4: 1, \mathrm{v} / \mathrm{v})$.

\section{2,3-DBPA}

The concentration was achieved in a first step using a vacuum evaporation system (Rotovapor R-210, BUCHI Labortechnik AG, Germany) till $2 \mathrm{~mL}$, followed in a second step by dryness under a stream of nitrogen.

\section{2,3-DBPA purification and concentration}

The residue dissolved in $50 \mathrm{~mL}$ hexane was purified on a glass column filled with activated Florisil and calcinated sodium sulfate, previously conditioned with $20 \mathrm{~mL}$ hexane. The 2,3-DBPA derivative was eluted with acetone, then concentrated till dryness and the residue was redissolved in $400 \mu \mathrm{L}$ ethyl acetate and $40 \mu \mathrm{L}$ triethylamine. The final solution was filtered through a $0.2 \mu \mathrm{m}$ regenerated cellulose microfilter (17 mm diameter, Spartan 13RC, Whatman $\mathrm{GmbH}$, Dassel, Germany) directly in a vial and analyzed by GC-MS/MS in SRM mode.

\section{Preparation of the calibration solutions}

A blank and 7 calibration levels in the range $0.1-7.5 \mathrm{mg} \mathrm{L}^{-1}$ were prepared in flasks of $250 \mathrm{~mL}$. In each flask, the following were added: $100 \mathrm{~mL}$ ultrapure water, $110 \mu \mathrm{L}$ IS of $10 \mathrm{mg} \mathrm{L}^{-1}$ and working solution II/I of AA ( $1 \mathrm{mg} \mathrm{L}^{-1} \mathrm{per}$ $10 \mathrm{mg} \mathrm{L}^{-1}$ ) according to the calibration level. These solutions were derivatized in the same manner as the derivatization steps described for bread, biscuits and other similar samples, without purification and the final residue was redissolved in $1000 \mu \mathrm{L}$ ethyl acetate and $100 \mu \mathrm{L}$ triethylamine.

\section{GC-MS/MS-SRM analysis}

The calibration solutions and the derivatized sample extracts were analyzed using a gas chromatograph (TRACE GC ULTRA) coupled with triple quadrupole mass spectrometer (TSQ Quantum XLS) from Thermo Fisher Scientific (USA). The analysis was performed in the electron impact positive ionization mode $\left(\mathrm{EI}^{+}\right)$; acquisition mode: "selected reaction monitoring-SRM" and ion scanning mode: "product".

The determination was carried out with a capillary column based on polyethylene-glycol $(30 \mathrm{~m} \times 0.25 \mathrm{~mm}$ internal diameter; $0.25 \mu \mathrm{m}$ ) (TraceGOLD ${ }^{\mathrm{TM}}$ TG-WaxMS, Thermo Fisher Scientific, USA). The mobile phase was helium with a constant flow rate of $1.6 \mathrm{~mL} \mathrm{~min}{ }^{-1} .1 \mu \mathrm{L}$ sample was injected in a Right PTV type injector using
TriPlus AS autosampler (Thermo Fisher Scientific, USA), in a split mode with a split ratio of 1:10 and injector temperature of $220^{\circ} \mathrm{C}$. Under these conditions, the retention time of AA and of the IS was of $10.65 \pm 0.5 \mathrm{~min}$. AA and IS were identified by the ion fragments corresponding to the derivatized ions, 2-BPA (2-bromopropenamide) and 2-BP $\left({ }^{13} \mathrm{C}_{3}\right) \mathrm{A}$. The fragmentation of the precursor ions with $\mathrm{m} / \mathrm{z}, 151$ and 154 was achieved with argon (1 mTorr), leading to the formation of product ions (daughter) with $m / z \quad 70$ (2-BPA) and $73\left(2-\mathrm{BP}\left({ }^{13} \mathrm{C}_{3}\right) \mathrm{A}\right)$, being used for quantification. The calculation of the AA concentration in the test samples was based on the ratio of the peak area corresponding to the product ions, with $\mathrm{m} / \mathrm{z}, 70$ and 73 for 2-BPA and 2-BP $\left({ }^{12} \mathrm{C}_{3}\right) \mathrm{A}$, respectively.

For bread samples and other similar products, AA concentration was calculated based on equation 1 , while for biscuits and other similar products using equation 2 .

$$
\begin{aligned}
& \mathrm{C}_{\text {calc. }}=\left[440 \times \mathrm{C} \times\left(100-\mathrm{U}_{1}\right)\right] /\left[\mathrm{w} \times\left(100-\mathrm{U}_{2}\right)\right] \mu \mathrm{g} \mathrm{kg}^{-1} \\
& \mathrm{C}_{\text {calc. }}=\mathrm{C} \times 440 / \mathrm{w} \mu \mathrm{g} \mathrm{kg}^{-1}
\end{aligned}
$$

where $\mathrm{C}$ is the 2-BPA concentration measured by the instrument in the food sample $\left(\mathrm{mg} \mathrm{L}^{-1}\right), \mathrm{C}_{\text {calc. }}$ is the 2-BPA concentration calculated for the food sample $\left(\mu \mathrm{g} \mathrm{kg}^{-1}\right), \mathrm{U}_{1}$ is the moisture content of the bread sample before drying $(\%), \mathrm{U}_{2}$ is the moisture content of the bread sample after drying (\%), w is the weight of the sample $(\mathrm{g}), 440$ is the final volume of the sample extract $(\mu \mathrm{L})$.

\section{Validation procedure}

The method was validated according to the guides and recommendations for methods validation. ${ }^{26-31}$ The following performance parameters were assessed:

\section{Calibration curve and linearity}

Calibration curve and linearity were verified by the method of least squares in the range $0.1-7.5 \mathrm{mg} \mathrm{L}^{-1}$, choosing the method of the internal standard. The calibration curve was obtained based on derivatized standard solutions and plotting the ratio of the peak area of 2-BPA and 2-BP $\left({ }^{13} \mathrm{C}\right) \mathrm{A}$ against the concentration of 2-BPA. The calibration model was considered correct if relative standard deviation (RSD) in repeatability conditions was within the limits of $\pm 15 \%$ for all the levels investigated. The correlation was assessed to be linear for a value greater than 0.99 for the correlation coefficient (R).

\section{Linearity range}

In order to establish higher values for the linearity range, the samples were spiked with working solution I of 
native AA $\left(10 \mathrm{mg} \mathrm{L}^{-1}\right)$ at different levels of concentration: $40 ; 75 ; 80 ; 150 ; 225$ and $300 \mu \mathrm{g} \mathrm{kg}^{-1}$ (bread and other similar products) and 250; 500; 750; 1000 and $2000 \mu \mathrm{g} \mathrm{kg}^{-1}$ (biscuits and other similar products). The ratio of the peak area of 2-BPA and 2-BP $\left({ }^{13} \mathrm{C}\right) \mathrm{A}$ against the concentration of 2-BPA from the food samples studied was plotted. The correlation was assessed to be linear for a value greater than 0.99 for the correlation coefficient (R).

\section{Sensitivity}

Sensitivity was characterized by limit of detection (LOD) and limit of quantification (LOQ). Assessment of LOD and LOQ for AA analysis in bread and similar products by GC-MS/MS were performed applying IUPAC approach, while ICH approach was used for biscuits and other similar products. The criteria imposed for LOQ were: precision (expressed as relative standard deviation, RSD $\leq 20 \%$ ) and accuracy (expressed as recovery in the range $80-120 \%$ ).

\section{Selectivity}

Selectivity was verified by observing the possible interference given by AA in bread, biscuits and other similar products. ${ }^{32}$ Specificity was achieved by SRM detection.

\section{Precision}

Precision was determined by repeatability (injection and analysis repeatability), inter-laboratory reproducibility and intermediate precision. Injection repeatability was achieved by carrying out between 9 and 10 consecutive injections in a short period of time (the same day). Analysis repeatability (intra-day) was determined by 5-6 repeated analyses of the same sample, in the same day by the same analyst and under the same experimental conditions. Inter-laboratory reproducibility (inter-day) was achieved through Food Analysis Performance Assessment Scheme (FAPAS) ${ }^{33}$ of the Central Science Laboratory (FERA). Intermediate precision (inter-day) was carried out by repeated analyses of the same sample in 3 different days by the same analyst and under the same experimental conditions. Repeatability and intermediate precision was expressed as RSD (\%), while interlaboratory reproducibility as z-score.

\section{Accuracy}

The accuracy of the method was evaluated with recovery and bias measurements for 2 reference test materials. The recovery percentage $(\mathrm{R} \%)$ of the method was established from minimum 6 repeated analysis of the same sample fortified with working solution II of AA at different concentrations.

\section{Robustness}

To assess the robustness of the method developed in the laboratory, the following parameters were varied: volume of hexane used in the purification of the extracts, derivatization time and mobile phase flow. It was considered that the method is robust for the parameters investigated, whether obtained under repeatability conditions RSD or reproducibility was below $2 \%$.

\section{Measurement uncertainty}

The uncertainty sources were identified and analyzed and the uncertainty budget was estimated, according to the reference documents. ${ }^{34,35}$ Expanded uncertainty $\left(\mathrm{U}_{\Delta}\right)$ was calculated by multiplying the combined standard uncertainty $\left(U_{c}\right)$ with a coverage factor $(k=2)$ for a confidence level of $95 \%$.

\section{Method application}

The validated and developed method was applied by analyzing different products presented in Tables 1-8. The AA level was also studied in different batches of the same brand ( 3 batches $\times 2$ types of breads; 2 batches $\times 5$ types of biscuits).

\section{Statistical analysis}

AA content was expressed as mean \pm standard deviation. The differences among sample groups were analyzed by one-way ANOVA (analysis of variance) followed by Tukey's test, $p<0.05$ was considered statistically significant.

Regarding validation parameters, average for concentration values, $\mathrm{C}_{\text {calc }}\left(\mu \mathrm{g} \mathrm{kg}^{-1}\right)$, standard deviation in repeatability $\mathrm{SD}(\mathrm{r})$ and reproducibility conditions $\mathrm{SD}(\mathrm{R})$ in $\mu \mathrm{g} \mathrm{kg}^{-1}$ as well as relative standard deviation in repeatability $\mathrm{RSD}(\mathrm{r})$ and reproducibility conditions $\mathrm{RSD}(\mathrm{R})$ in \% were calculated using Microsoft Excel. The repeatability and reproducibility limits in $\mu \mathrm{g} \mathrm{kg}^{-1}$ were also considered, where the ratio between repeatability and reproducibility is $2.8 \times \mathrm{SD}(\mathrm{r}) / \mathrm{SD}(\mathrm{R})$ for a confidence level of $95 \%$.

\section{Results and Discussion}

An overview of the test samples together with their coding and AA content is given in Tables 1-8.

\section{Calibration curve and linearity}

Linearity was investigated with the aid of a regression line with 7 calibration levels by the method of least squares. 
Table 1. Bread and similar products produced in the pilot plant

\begin{tabular}{|c|c|c|}
\hline & Main ingredients & $\mathrm{AA}^{\mathrm{a}} /\left(\mu \mathrm{g} \mathrm{kg}^{-1}\right)$ \\
\hline Pan bread & $\begin{array}{l}\text { white wheat flour type } 550, \\
\text { type } 2200\end{array}$ & $19.5 \pm 0.5 \mathrm{a}$ \\
\hline White bread & white wheat flour type 550 & $11.3 \pm 0.4 \mathrm{~b}$ \\
\hline Bread stick & $\begin{array}{c}\text { white wheat flour, dark wheat } \\
\text { flour }\end{array}$ & $26.2 \pm 1.1 \mathrm{c}$ \\
\hline Bread stick with olive & white wheat flour & $47.9 \pm 1.5 \mathrm{~d}$ \\
\hline Bread stick with nut & white wheat flour & $41.6 \pm 1.6 \mathrm{e}$ \\
\hline Bread stick with onion & white wheat flour & $87.3 \pm 1.8 \mathrm{f}$ \\
\hline
\end{tabular}

The calibration curve for the determination of $\mathrm{AA}$ in bread, biscuits and other similar products by GC-MS/MS analysis $(y=0.8613 x+0.0332)$ was linear over the range of 0.1-7.5 $\mathrm{mg} \mathrm{L}^{-1}$. $\mathrm{R}$ was between 0.9996-1, which proves a high linearity degree. The results showed that RSD(r) for all the levels of concentration studied ranged between 0.1 and $7.8 \%$, being within the limits of $\pm 15 \%$.

The linearity range was verified according to $\mathrm{ISO}^{36}$ for bread, biscuits and other similar products, respectively. The linearity range of the method for AA analysis was in the range of: $7.23-312.88 \mu \mathrm{g} \mathrm{kg}^{-1}(\mathrm{R}>0.998)$ for bread and similar products $(\mathrm{n}=23)$ and $17.59-2191.41 \mu \mathrm{g} \mathrm{kg}^{-1}$ $(\mathrm{R}>0.999)$ for biscuits and similar products $(n=42)$, respectively, $\mathrm{n}$ denotes the number of the analyzed samples. The results obtained are in line with a recent study, ${ }^{37}$ which reported an LC-MS/MS method for AA determination in different types of breads, with a linear range of up to $750 \mu \mathrm{g} \mathrm{kg}^{-1}$ food and a determination coefficient of 0.999 .

\section{Sensitivity}

For bread and similar products, LOD and LOQ obtained were 2.41 and $7.23 \mu \mathrm{g} \mathrm{kg}^{-1}$, respectively. For biscuits and similar products, LOD and LOQ were: 4.63 and $13.89 \mu \mathrm{g} \mathrm{kg}^{-1}$, respectively. LOQ values fulfilled the two criteria (RSD $<10 \%$ and recovery between 93.68 and $102.93 \%)$.

LOQ value for the present method was below $30 \mu \mathrm{g} \mathrm{kg}^{-1}$ which fulfils the criteria defined in European Commission recommendation on the monitoring of AA levels in food. ${ }^{23}$ Also, the results obtained are in accordance with a previous GC-MS study, which reported LOD and LOQ values of 2 and $5 \mu \mathrm{g} \mathrm{kg}{ }^{-1}$, respectively for bread samples. ${ }^{14}$

The working range reached from $2.41-2191.41 \mu \mathrm{g} \mathrm{kg}^{-1}$ AA in a food sample.

\section{Selectivity}

Selectivity was demonstrated by chromatographic separation of AA in the presence of other components from the food matrix (bread, biscuits and similar products).

For specificity, SRM detection and the use of IS method lead to a specific analysis. The retention time of AA within laboratory condition for the samples was almost identical with the retention time of the IS, which fits in the

Table 2. Bread and similar products (origin: retail store, produced in Romania)

\begin{tabular}{|c|c|c|c|}
\hline & $\begin{array}{l}\text { Sample, producer } \\
\text { code }\end{array}$ & Main ingredients & $\mathrm{AA}^{\mathrm{a}} /\left(\mu \mathrm{g} \mathrm{kg}^{-1}\right)$ \\
\hline White bread & $60 / \mathrm{R}$ & white wheat flour & $7.6 \pm 0.3 \mathrm{a}$ \\
\hline Round sliced bread & $31 / \mathrm{M}$ & whole wheat flour, dark wheat flour & $61.3 \pm 0.7 \mathrm{~b}$ \\
\hline \multirow[t]{3}{*}{ Whole toasted bread } & $32 / \mathrm{M}$ & \multirow{3}{*}{$\begin{array}{l}\text { whole wheat flour, dark wheat flour, malt flour } \\
\text { different batches }\end{array}$} & $115.2 \pm 0.3 \mathrm{c}$ \\
\hline & $33 / \mathrm{M}$ & & $49.7 \pm 0.3 \mathrm{~d}$ \\
\hline & $34 / \mathrm{M}$ & & $57.2 \pm 0.4 \mathrm{e}$ \\
\hline White bread with sage seeds & $35 / \mathrm{M}$ & white wheat flour & $28.0 \pm 0.5 \mathrm{f}$ \\
\hline Hypoglucidic sliced bread & $36 / \mathrm{M}$ & white wheat flour, bran, dark wheat flour & $104.5 \pm 0.3 \mathrm{~g}$ \\
\hline Whole wheat toasted bread & $37 / \mathrm{T}$ & whole wheat flour, fermented wheat flour, soy flour & $165.6 \pm 1.3 \mathrm{~h}$ \\
\hline \multirow[t]{3}{*}{ Whole wheat bread } & $38 / \mathrm{T}$ & \multirow{3}{*}{$\begin{array}{l}\text { whole wheat flour, fermented wheat flour, soy flour } \\
\text { different batches }\end{array}$} & $56.9 \pm 0.3 \mathrm{i}$ \\
\hline & $39 / \mathrm{T}$ & & $62.2 \pm 0.1 \mathrm{~b}$ \\
\hline & $47 / \mathrm{T}$ & & $79.8 \pm 0.2 \mathrm{j}$ \\
\hline German bread with seeds & $40 / \mathrm{T}$ & dark wheat flour, rye flour, wheat bran, wheat malt flour & $52.2 \pm 0.4 \mathrm{k}$ \\
\hline Transylvanian dark bread & $41 / \mathrm{U}$ & dark wheat flour & $21.3 \pm 0.11$ \\
\hline Bread with dark flour and bran & $42 / \mathrm{V}$ & dark and white wheat flour, wheat bran, malt flour & $37.4 \pm 0.1 \mathrm{~m}$ \\
\hline Whole toasted bread & $43 / \mathrm{S}$ & dark and white wheat flour, rye flour, soy flour, malt flour, rice flour & $46.0 \pm 0.3 n$ \\
\hline
\end{tabular}

aA: acrylamide; data shown as mean $\pm \mathrm{SD}(\mathrm{n}=3)$ for the amount of AA; means followed by different letters are significantly different $(p<0.05)$. 
tolerance of $\pm 0.5 \%$ imposed by Commission Decision $(2002 / 657 / \mathrm{CE}){ }^{30}{ }^{30}$ For AA quantification, ion $\mathrm{m} / \mathrm{z} 70$ (2-BPA) and ion $m / z, 73$ for IS $\left(2-\mathrm{BP}\left({ }^{12} \mathrm{C}_{3}\right) \mathrm{A}\right)$ were used.

The values obtained for injection and analysis repeatability, intermediate precision are presented in Table 9.

RSD(r) was between 0.71 and $3.30 \%$ for injection repeatability and between 0.44 and $4.90 \%$ for repeatability analysis, respectively. The $\mathrm{RSD}(\mathrm{R})$ intermediate precision was between 0.35 and $5.83 \%$. The applied method showed a good precision, RSD $<10 \%$ for AA analysis in bread, biscuits and similar products and the results were within the limits set by the following regulations: VICH GL $49,{ }^{28}$ CAC/GL $16,{ }^{29}$ EC. ${ }^{30}$
The AA result for crispbread sample from the FAPAS proficiency test (laboratory No. 24) showed a value of $193.77 \mu \mathrm{g} \mathrm{kg}^{-1}$ (z-score of 0.2 ), which fulfilled the acceptability criteria from the organization. ${ }^{33}$

\section{Method accuracy}

The bias obtained for the two reference materials were: $1.68 \%(\mathrm{n}=39)$ for $\mathrm{ERM}^{\circledR}-\mathrm{BD} 272$ crispbread and $2.52 \%(\mathrm{n}=30)$ for $\mathrm{ERM}^{\circledR}-\mathrm{BD} 274$ rusk, respectively. The described method demonstrated a satisfactory accuracy, between 99.59 and $102.28 \%$ for bread and similar products and between 95.44 and $104.63 \%$ for biscuits and similar products.

Table 3. Biscuits samples produced in the pilot plant

\begin{tabular}{lcc}
\hline & Main ingredients & $\mathrm{AA}^{\mathrm{a}} /\left(\mu \mathrm{gg}^{-1}\right)$ \\
\hline Biscuit from rice flour & $\mathrm{RF}^{\mathrm{b}}$, fat, sugar, eggs & $31.3 \pm 0.6 \mathrm{a}$ \\
Biscuit from white wheat flour & $\mathrm{WF}^{\mathrm{c}}$, fat, sugar, eggs & $152.0 \pm 2.9 \mathrm{~b}$ \\
Biscuit from white wheat and oat flour & $\mathrm{WF}^{\mathrm{c}}$ 75\%, OF 25\%, fat, sugar, eggs & $148.9 \pm 2.7 \mathrm{~b}$ \\
Biscuit from white wheat and oat flour & $\mathrm{WF}^{\mathrm{c}}$ 50\%, OF 50\%, fat, sugar, eggs & $359.0 \pm 4.2 \mathrm{c}$ \\
Biscuit from whole oat flour & $\mathrm{OF}^{\mathrm{d}}$ 100\%, fat, sugar, eggs & $346.3 \pm 2.3 \mathrm{~d}$ \\
Biscuit from oat and bran flour & $\mathrm{OF}^{\mathrm{d}}$ 70\%, oat bran 30\%, fat, sugar, eggs & $<\mathrm{LOQ}^{\mathrm{e}} \mathrm{e}$ \\
\hline
\end{tabular}

${ }^{a} \mathrm{AA}$ : acrylamide; data shown as mean $\pm \mathrm{SD}(\mathrm{n}=3)$ for the amount of AA; means followed by different letters are significantly different $(p<0.05)$; ${ }^{\mathrm{b} F}$ : rice flour; ${ }^{\mathrm{c} W F}$ : wheat flour; ${ }^{\mathrm{d}} \mathrm{OF}$ : oat flour; ${ }^{\mathrm{e}} \mathrm{LOQ}$ : limit of quantification.

Table 4. Biscuits samples (origin: retail store, produced in different countries)

\begin{tabular}{|c|c|c|c|}
\hline & $\begin{array}{l}\text { Sample, producer code, } \\
\text { country }\end{array}$ & Main ingredients & $\mathrm{AA}^{\mathrm{a}} /\left(\mu \mathrm{g} \mathrm{kg}^{-1}\right)$ \\
\hline Biscuit from oat & 50/E/Turkey & $\mathrm{OF}^{\mathrm{b}}, \mathrm{WF}^{\mathrm{c}}, \mathrm{WWF}^{\mathrm{d}}$, fat, sugar, eggs & $702.2 \pm 0.7 \mathrm{a}$ \\
\hline Biscuit with wheat bran & 51/B/Romania & $\mathrm{WF}^{\mathrm{c}}$, wheat bran, sugar, fat, barley malt extract, wheat fiber & $329.7 \pm 2.7 b$ \\
\hline \multirow[t]{2}{*}{ Digestive biscuit with cinnamon } & 52a/M/Romania & \multirow{2}{*}{$\begin{array}{l}\mathrm{WWF}^{\mathrm{b}} \text {, fats, sugar, wheat bran, malt extract } \\
\text { different batches }\end{array}$} & $1213.6 \pm 6.7 \mathrm{c}$ \\
\hline & 52b/M/Romania & & $1665.2 \pm 17.9 \mathrm{~d}$ \\
\hline Digestive biscuit & 53/E/Turkey & $\begin{array}{l}\text { WWF', fats, sugar, egg, barley malt extract, wheat bran, milk } \\
\text { powder }\end{array}$ & $487.7 \pm 3.2 \mathrm{e}$ \\
\hline Biscuit with salt & 56/H/Romania & $\mathrm{WF}^{\mathrm{c}}$ flour, oil, barley malt extract, egg, salt & $355.9 \pm 0.7 \mathrm{f}$ \\
\hline $\begin{array}{l}\text { Biscuit from oat flour and fruit jam } \\
\text { (fasting) }\end{array}$ & 57/C/Moldavia & $\mathrm{WF}^{\mathrm{c}}, \mathrm{OF}^{\mathrm{b}}$, sugar, fat, fruit jam & $263.1 \pm 2.8 \mathrm{~g}$ \\
\hline $\begin{array}{l}\text { Biscuit from whole oat and fruits, } \\
\text { without gluten (fasting) }\end{array}$ & 69/A/Scotland & $\mathrm{OF}^{\mathrm{b}}$, palm oil, raisins, sugar, Tapioca starch & $1774.2 \pm 13.1 \mathrm{~h}$ \\
\hline Biscuit from BIO whole oat & 70/P/Germany & $\mathrm{OF}^{\mathrm{b}}, \mathrm{WF}^{\mathrm{c}}$, sugar, fat, egg powder, maize starch & $46.8 \pm 1.2 \mathrm{i}$ \\
\hline Biscuit with oat & 71/Z/Romania & $\mathrm{WF}^{\mathrm{c}}, \mathrm{OF}^{\mathrm{b}}$, sugar, palm oil, wheat starch & $1220.7 \pm 17.7 \mathrm{j}$ \\
\hline \multirow{2}{*}{$\begin{array}{l}\text { Digestive biscuit with cereals, raisins, } \\
\text { orange and lemon }\end{array}$} & 72a/M/Romania & \multirow{2}{*}{$\begin{array}{l}\text { cereals, raisins, orange and lemon } \\
\text { different batches }\end{array}$} & $2305.3 \pm 2.7^{\mathrm{e}} \mathrm{k}$ \\
\hline & 72b/M/Romania & & $2405.0 \pm 1.4^{\mathrm{e}} 1$ \\
\hline \multirow{2}{*}{$\begin{array}{l}\text { Biscuit with whole cereals and } \\
\text { cranberry red, vitamins and minerals }\end{array}$} & 73a/H/Romania & \multirow{2}{*}{$\begin{array}{l}\text { whole cereals and cranberry red, vitamins, minerals } \\
\text { different batches }\end{array}$} & $702.3 \pm 13.5 \mathrm{a}$ \\
\hline & 73b/H/Romania & & $788.3 \pm 6.8 \mathrm{~m}$ \\
\hline \multirow{2}{*}{$\begin{array}{l}\text { Biscuit with whole cereals, nuts and } \\
\text { honey, vitamins and minerals }\end{array}$} & 74a/H/Romania & \multirow{2}{*}{$\begin{array}{l}\text { whole cereals, nuts and honey, vitamins, minerals } \\
\text { different batches }\end{array}$} & $448.6 \pm 2.5 \mathrm{n}$ \\
\hline & 74b/H/Romania & & $242.7 \pm 2.7 \mathrm{o}$ \\
\hline
\end{tabular}

${ }^{\mathrm{a} A A}$ : acrylamide; data shown as mean $\pm \mathrm{SD}(\mathrm{n}=3)$ for the amount of AA; means followed by different letters are significantly different $(p<0.05)$; ${ }^{\mathrm{O} O F}$ : oat flour; ${ }^{\mathrm{c} W F}$ : wheat flour; ${ }^{\mathrm{d} W W F}$ : whole wheat flour; ${ }^{\mathrm{t}}$ the AA levels were higher than the maximum value of the working range, but in order to quantify it, the samples weight taken for analysis was lower $(0.75 \mathrm{~g}$ instead of $1.5 \mathrm{~g})$. 
Table 5. Biscuits for infants and young children (origin: retail store, produced in different countries)

\begin{tabular}{|c|c|c|c|}
\hline & Sample, producer code, country & Main ingredient & $\mathrm{AA}^{\mathrm{a}} /\left(\mu \mathrm{g} \mathrm{kg}^{-1}\right)$ \\
\hline Biscuit with vitamins and minerals & 89/I/Romania & $\begin{array}{l}\text { WF }^{\mathrm{b}} \text {, fats, sugar, maize starch, egg } \\
\text { powder, milk powder, vitamins }\end{array}$ & $801.7 \pm 8.2 \mathrm{a}$ \\
\hline Biscuit with apple for children & 91/J/Switzerland & $\begin{array}{c}\mathrm{WF}^{\mathrm{b}}, \mathrm{WWF}^{\mathrm{c}} \text {, apple juice, apple } \\
\text { extract }\end{array}$ & $69.7 \pm 1.9 \mathrm{~b}$ \\
\hline First biscuit of the child & 92/J/Switzerland & $\begin{array}{l}\mathrm{WF}^{\mathrm{b}} \text {, sugar, wheat starch, milk } \\
\text { powder, vitamin B1 }\end{array}$ & $<\mathrm{LOQ}^{\mathrm{d}} \mathrm{c}$ \\
\hline $\begin{array}{l}\text { Biscuit enriched with } 5 \text { vitamins, } \\
\text { calcium and iron }\end{array}$ & 93/K/Italy & $\begin{array}{l}\mathrm{WF}^{\mathrm{b}} \text {, sugar, milk fat, wheat starch, } \\
\text { honey, vitamins, minerals }\end{array}$ & $117.7 \pm 2.8 \mathrm{~d}$ \\
\hline $\begin{array}{l}\text { Biscuit enriched with } 5 \text { vitamins, } \\
\text { calcium and iron for young children }\end{array}$ & 94/K/Italy & $\begin{array}{l}\mathrm{WF}^{\mathrm{b}} \text {, sugar, oil, milk powder, rice } \\
\text { malt extract, vitamins, minerals }\end{array}$ & $37.8 \pm 0.3 \mathrm{e}$ \\
\hline
\end{tabular}

${ }^{\mathrm{a} A A}$ : acrylamide; data shown as mean $\pm \mathrm{SD}(\mathrm{n}=6)$ for the amount of AA; means followed by different letters are significantly different $(p<0.05)$; ${ }^{\text {bWF}}$ : wheat flour; ${ }^{\mathrm{C}} \mathrm{WWF}$ : whole wheat flour; ${ }^{\mathrm{d}} \mathrm{LOQ}$ : limit of quantification.

Table 6. Sandwich biscuits with cream filling (origin: retail store)

\begin{tabular}{lccc}
\hline & Sample, producer code, country & Main ingredients & $\mathrm{AA}^{\mathrm{a}} /\left(\mu \mathrm{g} \mathrm{kg} \mathrm{k}^{-1}\right)$ \\
\hline Biscuit with cocoa cream & $80 / \mathrm{L} /$ Romania & $\mathrm{WF}^{\mathrm{b}}$, fat, sugar & $527.2 \pm 5.8 \mathrm{a}$ \\
Biscuit with honey and milk cream & $81 / \mathrm{M} /$ Romania & $\mathrm{WF}^{\mathrm{b}}$, fat, sugar, honey, powder milk, starch & $570.4 \pm 7.2 \mathrm{~b}$ \\
Biscuit with sour cream & 82/B/Romania & $\mathrm{WF}^{\mathrm{b}}$, sugar, fat, cocoa powder, milk powder, & $112.6 \pm 3.1 \mathrm{c}$ \\
& & cream powder & \\
Vanilla biscuit with cocoa cream & 76a/I/Romania & $\mathrm{WF}^{\mathrm{b}}$, sugar, palm oil, maize starch, cocoa & $243.7 \pm 5.8 \mathrm{~d}$ \\
& 76b/I/Romania & different batches & $177.8 \pm 6.0 \mathrm{e}$ \\
\hline
\end{tabular}

${ }^{\mathrm{a} A A}$ : acrylamide; data shown as mean $\pm \mathrm{SD}(\mathrm{n}=5)$ for the amount of AA; means followed by different letters are significantly different $(p<0.05)$; ${ }^{\mathrm{W} F}$ : wheat flour.

Table 7. Crackers samples (origin: retail store)

\begin{tabular}{lccc}
\hline & Sample, producer code, country & Main ingredients & $\mathrm{AA}^{\mathrm{a}} /\left(\mathrm{gg} \mathrm{kg}^{-1}\right)$ \\
\hline Cheese cracker & $3437 / \mathrm{O} /$ Romania & $\mathrm{WF}^{\mathrm{b}}$, oil, cheese powder, pea flour, corn starch & $347.8 \pm 4.3 \mathrm{a}$ \\
Caraway cracker & $3438 / \mathrm{O} /$ Romania & $\mathrm{WF}^{\mathrm{b}}$, oil, caraway, cheese powder, pea flour & $366.1 \pm 21.3 \mathrm{a}$ \\
\hline
\end{tabular}

${ }^{a}$ AA: acrylamide; data shown as mean \pm SD $(n=6)$ for the amount of AA; values with the same letter denote no significant difference $(p>0.05)$ between

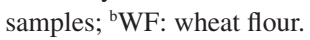

Table 8. Gingerbread samples (origin: retail store)

\begin{tabular}{lccc}
\hline & Sample, producer code, country & Main ingredients & $\mathrm{AA}^{\mathrm{a}} /\left(\mu \mathrm{g} \mathrm{kg}^{-1}\right)$ \\
\hline Gingerbread & $58 / \mathrm{N} /$ Romania & $\mathrm{WF}^{\mathrm{b}}$, rye flour, sugar, honey & $955.5 \pm 2.9 \mathrm{a}$ \\
Gingerbread & $59 / \mathrm{C} /$ Moldavia & $\mathrm{WF}^{\mathrm{b}}$, sugar, sorbitol & $588.8 \pm 16.8 \mathrm{~b}$ \\
Gingerbread & $90 / \mathrm{C} /$ Moldavia & $\mathrm{WF}^{\mathrm{b}}$, sugar, sorbitol & $349.5 \pm 3.9 \mathrm{c}$ \\
\hline
\end{tabular}

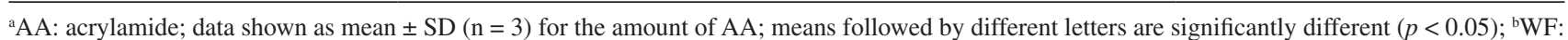
wheat flour.

\section{Robustness}

The small variations in the volume of hexane used in the purification of the extracts, derivatization time and mobile phase flow are not susceptible to variations in the area corrected. Standard deviation was between 1.79 and $2.07 \%$.

\section{Measurement uncertainty}

The uncertainty of results for AA determination in bread, biscuits and similar products by GC-MS/MS was $\pm 21 \%$ as estimated by budget uncertainty. 
Table 9. Performance parameters of the method

\begin{tabular}{|c|c|c|c|c|c|c|}
\hline \multirow[b]{2}{*}{ Performance parameter } & & \multicolumn{5}{|c|}{ Sample } \\
\hline & & $\begin{array}{l}\text { Bread and similar } \\
\text { products }\end{array}$ & Biscuit & Sandwich biscuit & Cracker & Gingerbread \\
\hline \multicolumn{7}{|c|}{ Precision } \\
\hline \multirow[t]{2}{*}{ Injection repeatability } & $\mathrm{AA} /\left(\mathrm{mg} \mathrm{L}^{-1}\right)$ & $\begin{array}{c}0.040 \\
(\mathrm{n}=9)\end{array}$ & $\begin{array}{c}0.210-5.658 \\
(\mathrm{n}=10)\end{array}$ & $\begin{array}{c}0.611-1.960 \\
(\mathrm{n}=9-10)\end{array}$ & $\mathrm{NC}$ & $\mathrm{NC}$ \\
\hline & $\mathrm{RSD}(\mathrm{r}) / \%$ & 3.30 & $0.71-1.55$ & $1.14-1.47$ & $\mathrm{NC}$ & $\mathrm{NC}$ \\
\hline \multirow{2}{*}{$\begin{array}{l}\text { Analysis repeatability } \\
\text { (intra-day) }\end{array}$} & $\mathrm{AA} /\left(\mu \mathrm{g} \mathrm{kg}^{-1}\right)$ & $\begin{array}{c}7.58-157.10 \\
(\mathrm{n}=5-6)\end{array}$ & $\begin{array}{c}30.91-1778.97 \\
\quad(n=6)\end{array}$ & $\begin{array}{c}113.97-1065.47 \\
(\mathrm{n}=5-6)\end{array}$ & $\begin{array}{l}347.78 \\
(\mathrm{n}=6)\end{array}$ & $\begin{array}{c}608.62-1318.48 \\
(\mathrm{n}=5-6)\end{array}$ \\
\hline & $\mathrm{RSD}(\mathrm{r}) / \%$ & $0.53-3.33$ & $0.74-4.90$ & $0.95-1.55$ & 1.24 & $0.44-2.93$ \\
\hline \multirow{2}{*}{$\begin{array}{l}\text { Intermediate precision } \\
\text { (inter-day) }\end{array}$} & $\mathrm{AA} /\left(\mu \mathrm{kg}^{-1}\right)$ & $\begin{array}{c}19.50-73.62 \\
(\mathrm{n}=3-4)\end{array}$ & $\begin{array}{c}37.60-1221.29 \\
(\mathrm{n}=3)\end{array}$ & $\begin{array}{c}113.16-576.69 \\
(\mathrm{n}=2-3)\end{array}$ & $\mathrm{NC}$ & $\begin{array}{c}349.70-954.49 \\
(\mathrm{n}=2-3)\end{array}$ \\
\hline & $\mathrm{RSD}(\mathrm{R}) / \%$ & $1.17-5.83$ & $0.94-5.34$ & $1.53-3.84$ & $\mathrm{NC}$ & $0.35-1.76$ \\
\hline
\end{tabular}

AA: acrylamide; NC: not calculated; RSD(r): relative standard deviation in repeatability; RSD(R): relative standard deviation reproducibility conditions.

\section{Method application}

As it can be noticed from Tables 1-8, the results for the AA content in the different food samples studied, varied greatly not only from one type of product to another one, but also in the same type of product coming from different brands or the same product with different batches. From the 49 types of bread, biscuits, crackers and gingerbread analyzed coming from 20 different suppliers, 16 of them (4 bread samples, 11 biscuits and sandwich biscuits and 1 biscuit for infants and young children) had an AA level higher than the "indicative values" provided in the Commission Recommendation (EC 2013). ${ }^{6}$ The indicative values were for soft bread obtained from wheat flour were set at a value of $80 \mu \mathrm{g} \mathrm{kg}^{-1}$, biscuits for infants and young children at $200 \mu \mathrm{g} \mathrm{kg}^{-1}$, biscuits and crackers at $500 \mu \mathrm{g} \mathrm{kg}^{-1}$ and gingerbread at $1000 \mu \mathrm{g} \mathrm{kg}^{-1}$, respectively.

Bread products manufactured in the pilot plant under controlled conditions (Table 1) do not exceed the indicative values, except the bread sample prepared with onion. This could be explained by the fact that onion contributes to AA formation. It was shown ${ }^{38}$ that onion among other ingredients used for seasoning increased the AA content. Analysis of the AA content in the same type of food from the market (the same receipt and manufacturing process according to the producer declaration) with different batches showed differences in the AA content. For example, for 3 batches of bread (code 32, 33 and 34) coming from the same producer, $\mathrm{M}$, the AA level showed significant differences, while for another 3 batches of bread (code 38, 39 and 47, from producer T), the AA levels showed similar values (Table 2). This could be explained by the technological conditions (temperature, time) which could vary or by variation in the quality of the raw materials.
Adult chronic dietary exposure estimated by EFSA ${ }^{39}$ was between 0.4 and $0.9 \mu \mathrm{g} \mathrm{kg}^{-1}$ bw per day. Considering than in Romania, the bread intake for an adult weighing $80 \mathrm{~kg}$ is $300 \mathrm{~g}$ per day and based on the average level of AA obtained in this study for the breads from the market $\left(62.99 \mu \mathrm{g} \mathrm{kg}^{-1}\right.$, Table 2), it can be concluded that bread contributes to a chronic dietary exposure of $0.9 \mu \mathrm{g} \mathrm{kg}^{-1}$ bw per day with about $26 \%$. The same procedure was applied for biscuits and similar products. Thus, for a daily intake of $5.8 \mathrm{~g}$ and an average for AA obtained for these products (456.01 $\mathrm{g} \mathrm{kg}^{-1}$, Tables 3-8), the biscuits contributes to a chronic dietary exposure of $0.9 \mu \mathrm{g} \mathrm{kg}^{-1}$ bw per day with about $3.7 \%$.

The AA content obtained for bakery products are in accordance with the data presented in literature (Table 10).

\section{Conclusions}

The proposed GC-MS/MS method corresponds to the validation parameters imposed and it was applied with good results to determine AA content in bread, biscuits and other similar products. The LOD and LOQ values were 2.41 and $7.23 \mu \mathrm{g} \mathrm{kg}^{-1}$ for bread and similar products, while for biscuits and similar products were 4.63 and $13.89 \mu \mathrm{g} \mathrm{kg}^{-1}$, respectively. This study assesses the presence of AA in foods found on the Romanian market. Taking into account the consumption of bakery products among adults and children, establishment of measures is necessary in order to protect consumer health. In this respect, an important measure is to control in order to avoid the sale of foods with high levels of AA.

Considering all of the above data for method performance and proficiency test, the GC-MS/MS method and sample pretreatment employed in the present work can be regarded as being sensible, precise and robust. 
Table 10. Survey of AA content in bakery products

\begin{tabular}{|c|c|c|}
\hline Sample & $\mathrm{AA} /\left(\mu \mathrm{g} \mathrm{kg}^{-1}\right)$ & Reference \\
\hline \multirow{11}{*}{$\begin{array}{l}\text { Bread and similar } \\
\text { products }\end{array}$} & $<10-3.200$ & 40 \\
\hline & 446 & 41 \\
\hline & $126-274$ & 42 \\
\hline & $228-257$ & 43 \\
\hline & $49-235$ & 44 \\
\hline & 7.4-175 & 45 \\
\hline & 87 & 46 \\
\hline & 75 & 47 \\
\hline & 42 & 39 \\
\hline & 11.3-87.3 (pilot plant) & this study \\
\hline & 7.6-165.6 (market) & this study \\
\hline \multirow{10}{*}{$\begin{array}{l}\text { Biscuit and similar } \\
\text { products }\end{array}$} & $18-3324$ & 40 \\
\hline & $83-423$ & 46 \\
\hline & 350 & 41 \\
\hline & $313-317$ & 42 \\
\hline & $204-284$ & 44 \\
\hline & 231 & 39 \\
\hline & 237 & 47 \\
\hline & $131-163$ & 43 \\
\hline & $<4.63-359.0$ (pilot plant) & this study \\
\hline & $<4.63-2405.0$ (market) & this study \\
\hline \multirow{7}{*}{ Gingerbread } & 910 & 48 \\
\hline & 501 & 49 \\
\hline & 437 & 44 \\
\hline & 407 & 39 \\
\hline & 387 & 47 \\
\hline & 300 & 43 \\
\hline & 349.5 63-955.5 (market) & this study \\
\hline
\end{tabular}

AA: acrylamide.

\section{Acknowledgments}

This study was financially supported by the Ministry of National Education-State Authority for Scientific Research, Technological Development and Innovation, through Nucleu Program PN 1248 (contract No. 48N/2012).

\section{References}

1. International Agency for Research on Cancer (IARC); Monographs on the Evaluation of Carcinogenic Risks of Chemicals to Humans, Vol. 60; Lyon, France, 1994, p. 389.

2. Friedman, M.; J. Agric. Food Chem. 2003, 51, 4504.

3. Joint FAO/WHO Expert Committee on Food Additives (JECFA); Evaluation of Certain Food Contaminants: SixtyFourth Report of the Joint FAO/WHO Expert Committee on Food Additives; WHO: Geneva, 2006. Available at http://apps. who.int/iris/bitstream/10665/43258/1/WHO_TRS_930_eng. pdf accessed on February 7, 2016.

4. Joint FAO/WHO Expert Committee on Food Additives (JECFA);
Evaluation of Certain Contaminants in Food: Seventy-Second Report of the Joint FAO/WHO Expert Committee on Food Additives; WHO: Geneva, 2011. Available at http://www. inchem.org/documents/jecfa/jecmono/v959je01.pdf accessed on February 7, 2016.

5. US Food and Drug Administration; Draft Guidance for Industry: Acrylamide in Foods; 2013. Available at www.fda.gov/Food/GuidanceRegulation/ GuidanceDocumentsRegulatoryInformation/ucm374524.htm accessed on February 7, 2016.

6. European Commission; Commission Recommendation on Investigations into Levels of Acrylamide in Food; (2013/647/ UE), 2013. Available at http://eur-lex.europa.eu/legal-content/ EN/TXT/PDF/?uri=CELEX:32013H0647\&from=EN accessed on February 7, 2016.

7. European Commission; Opinion of the Scientific Committee on Food on New Findings Regarding the Presence of Acrylamide in Food; 2002. Available at http://ec.europa.eu/food/fs/sc/scf/ out131_en.pdf accessed on February 7, 2016.

8. Hogervorst, J. G. F.; Baars, B. J.; Schouten, L. J.; Konings, E. J. M.; Goldbohm, R. A.; van den Brandt, P. A.; Crit. Rev. Toxicol. 2010, 40, 485 .

9. Oracz, J.; Nebesny, E.; Zyzelewicz, D.; Talanta 2011, 86, 23.

10. Elbashir, A. A.; Omar, M. M. A.; Ibrahim, W. A. W.; Schmitz, O. J.; Aboul-Enein, H. Y.; Crit. Rev. Anal. Chem. 2014, 44, 107.

11. Hu, Q.; Xu, X.; Fu, Y.; Li, Y.; Food Control 2015, 56, 135.

12. Tareke, E.; Rydberg, P.; Karlsson, P.; Eriksson, S.; Trnqvist, M.; J. Agric. Food Chem. 2002, 50, 4998.

13. Nemato, S.; Takatsuki, S.; Sasaki, K.; Maitani, T.; J. Food Hyg. Soc. Jpn. 2002, 43, 371.

14. Pittet, A.; Périsset, A.; Oberson, J. M.; J. Chromatogr. 2004, 1035, 123.

15. Cheng, W. C.; Hsiao, S. W.; Chou, S. S.; Sun-Hwang, L.; Lu, T. J.; Yeh, A.-I.; J. Food Drug Anal. 2006, 14, 207.

16. Omar, M. M. A.; Ibrahim, W. A. W.; Elbashir, A. A.; Food Chem. 2014, 158, 302.

17. Zhu, Y. H.; Li, G.; Duan, Y. P.; Chen, S. Q.; Zhang, C.; Li, Y. F.; Food Chem. 2008, 109, 899.

18. Claus, A.; Weisz, G. M.; Kammerer, D. R.; Carle, R.; Schieber, A.; Mol. Nutr. Food Res. 2005, 49, 918.

19. Hoenicke, K.; Gatermann, R.; Harder, W.; Hartig, L.; Anal. Chim. Acta 2004, 520, 207.

20. Nielsen, N. J.; Granby, K.; Hedegaard, R. V.; Skibsted, L. H.; Anal. Chim. Acta 2006, 557, 211.

21. Zhang, Y.; Jiao, J.; Cai, Z.; Zhang, Y.; Ren, Y.; J. Chromatogr. A 2007, 1142, 194.

22. Wenzl, T.; Karasek, L.; Rosen, J.; Hellenaes, K.-E.; Crews, C.; Castle, L.; Anklam, E.; J. Chromatogr. A 2006, 1132, 211.

23. European Commission; Commission Recommendations of 2 June 2010 on the Monitoring of Acrylamide Levels in Food; Official Journal of the European Union, L 137, 4-10 (2010/307/ 
EU), 2010. Available at http://eur-lex.europa.eu/legal-content/ EN/TXT/PDF/?uri=CELEX:32010H0307\&from=EN accessed on February 7, 2016.

24. Negoita, M.; Catana, M.; Iorga, E.; Catana, L.; Adascalului, A.; Belc, N.; Rom. Biotechnol. Lett. 2014, 19, 9561.

25. Negoita, M.; Adascalului, A.; Iorga, E.; Catana, L.; Catana, M.; Belc, N.; Rev. Chim. 2015, 66, 464.

26. ISO/IEC 17025: General Requirements for the Competence of Testing and Calibration Laboratories, ISO: Geneva, 2005.

27. International Conference on Harmonisation of Technical Requirements for Registration of Pharmaceuticals For Human Use (ICH); Validation of Analytical Procedures: Text and Methodology Q2(R1); ICH: London, 2005.

28. Veterinary International Conference on Harmonization (VICH); VICH GL49-Guidance for Industry Studies to Evaluate the Metabolism and Residue Kinetics of Veterinary Drugs in FoodProducing Animals: Validation of Analytical Methods Used in Residue Depletion Studies, VICH: Rockville, 2015.

29. CAC/GL 16: Codex Guidelines for the Establishment of a Regulatory Programme for Control of Veterinary Drug Residues in Foods, Part III-Attributes of Analytical Methods for Residue of Veterinary Drugs in Foods, Rome, 1993, p. 41.

30. European Commission; Commission Decision of 12 August 2002 Implementing Council Directive 96/23/EC Concerning the Performance of Analytical Methods and the Interpretation of Results, (2002/657/CE), L 221/8-36. Available at http://eurlex.europa.eu/legal-content/EN/TXT/PDF/?uri=CELEX:3200 2D0657\&from=EN accessed on February 7, 2016.

31. ISO/TS 21748: Guidance for the Use of Repeatability, Reproducibility and Trueness Estimates in Measurement Uncertainty Estimation, ISO: Geneva, 2004.

32. Vessman, J.; Stefan, R. I.; van Staden, J. F.; Danzer, K.; Lindner, W.; Burns, D. T.; Fajgelj, A.; Müller, H.; Pure Appl. Chem. 2001, $72,1381$.

33. FAPAS: Acrylamide Report 3056; FAPAS Proficiency Testing, Fera Science Ltd: Sans Hutton, York, UK, 2015.

34. EURACHEM/CITAC Guide; Quantifying Uncertainty in Analytical Measurement, $3^{\text {rd }}$ ed.; UK, 2011.

35. ISO/IEC Guide 98-3:2008: Uncertainty of Measurement -- Part 3: Guide to the Expression of Uncertainty in Measurement (GUM:1995), ISO: Geneva, 2008.

36. ISO 8466-1:1990: Water Quality. Calibration and Evaluation of Analytical Methods and Astimation of Performance Characteristics, Part 1: Statistical Evaluation of the Linear Calibration Function, ISO: Geneva, 2010.

37. Alpözen, E.; Güven, G.; Özdestan, Ö.; Üren, A.; Acta Aliment.
2015, 44, 221.

38. Tateo, F.; Bononi, M.; Andreoli, G.; J. Food Compos. Anal. 2007, 20, 232.

39. European Food Safety Authority (EFSA); Outcome of the Public Consultation on the Draft Scientific Opinion of the EFSA Panel on Contaminants in the Food Chain on Acrylamide in Food; EFSA Supporting Publication: Parma, 2015. Available at http:// www.efsa.europa.eu/sites/default/files/scientific_output/files/ main_documents/817e.pdf accessed on February 7, 2016.

40. Krishnakumar, T.; Visvanathan, R.; J. Food Process. Technol. 2012, 5, 344.

41. Keramat, J.; LeBail, A.; Prost, C.; Soltanizadeh, N.; Food Bioprocess Technol. 2011, 4, 340.

42. European Food Safety Authority (EFSA); Scientific Report of EFSA: Results on the Monitoring of Acrylamide Levels in Food; The EFSA Scientific Report 285: Parma, 2009, p. 1. Available at http://www.efsa.europa.eu/sites/default/files/scientific_output/ files/main_documents/293r.pdf accessed on February 7, 2016.

43. Mojska, H. In Acrylamide in Food; Gökmen, V., ed.; Academic Press: Amsterdam, 2015, p. 39.

44. European Food Safety Authority (EFSA); Scientific Report of EFSA: Results on Acrylamide Levels in Food from Monitoring Year 2008; EFSA Journal: Parma, 2010, p. 1599. Available at http://www.efsa.europa.eu/sites/default/files/scientific_output/ files/main_documents/1599.pdf accessed on February 7, 2016.

45. Sadd, P.; Hamlet, C. In Chemistry and Safety of Acrylamide in Food, Vol. 561; Friedman, M.; Mottram, D., eds.; Springer: New York, 2005, p. 415.

46. Ruan-Henares, J.-A.; Arribas-Lorenzo, G.; Morales, F. J.; Food Addit. Contam. 2007, 24, 343.

47. European Food Safety Authority (EFSA); Scientific Report of EFSA: Update on Acrylamide Levels in Food from Monitoring Years 2007 to 2010; EFSA Journal: Parma, 2012, p. 2938. Available at http://www.efsa.europa.eu/sites/default/files/ scientific_output/files/main_documents/2938.pdf accessed on February 7, 2016.

48. Amrein, T. M.; Schönbächler, B.; Escher, F.; Amadò, R. In Chemistry and Safety of Acrylamide in Food, Vol. 561; Friedman, M.; Mottram, D., eds.; Springer: New York, 2005, p. 431.

49. Amrein, T. M.; Schönbächler, B.; Escher, F.; Amadò, R.; J. Agric. Food Chem. 2004, 52, 4282.

Submitted: November 24, 2015

Published online: February 18, 2016 